\title{
Delirium in terminal cancer inpatients: short-term survival and missed diagnosis
}

\author{
Oscar Rodríguez-Mayoral,' Francisco Reyes-Madrigal, ${ }^{2}$ Silvia Allende-Pérez,' Emma Verástegui'
}

Servicio de Cuidados Paliativos, Instituto Nacional de Cancerología, Ciudad de México, México.

2 Laboratorio de Psiquiatría Experimental, Instituto Nacional de Neurología y Neurocirugía Manuel Velasco Suárez, Ciudad de México, México.

\section{Correspondence:}

Óscar Rodríguez-Mayoral

Servicio de Cuidados Paliativos, Instituto Nacional de Cancerología.

Av. San Fernando No. 22 Col. Sección XVI, Delegación Tlalpan, C.P. 14080 , Ciudad de México, México.

Phone: (55) 5628-0400 Ext. 50008

Email: orodriguezm@incan.edu.mx; oscroma@gmail.com

Received: 22 June 2017

Accepted: 29 January 2018

\section{Citation:}

Rodríguez-Mayoral, O., Reyes-Madrigal, F., Allende-Pérez, S., Verástegui, E. Delirium in terminal cancer inpatients: short-term survival and missed diagnosis. Salud Mental, 41 (1), 25-29. doi: 10.17711/SM.0185-3325.2018.005

\section{(c) (i) (5)}

\begin{abstract}
Introduction. Delirium is a neurocognitive disorder, frequently present in advanced cancer patients. It morbidity, mortality, health expenditure, and causes distress to patients, family members, and health care professionals. Despite its impact, the disorder is still underdiagnosed, and consequently, mistreated. Objective. To describe the prevalence, clinical features, impact on the survival and percentage of missed diagnosis of delirium, in palliative care inpatients treated in a tertiary center. Method. We conducted a prospective study, including all the inpatients referred to the Palliative Care Service of the Instituto Nacional de Cancerología in Mexico, from August, 2014 to March, 2015. As a first step, we collected clinical and sociodemographic data, and determined the presence/absence of delirium, using the Confusion Assessment Method. Then, we reviewed the clinical file to determine if a previous delirium diagnosis was stablished by the primary referring team. Finally, thirty days after the initial assessment, we contacted the patients in order to know their survival status (alive/ death). We performed a survival analysis to compare mortality among patients with delirium/non-delirium, and reported the percentage of delirium missed diagnosis. Results. We included 174 patients, $40.2 \%$ were diagnosed with delirium. Mean survival time in patients with delirium was 11 days, while in non-delirium patient's mean survival time was 21 days; Log Rank $23.50, p<.001$. We found a $73 \%$ of missed delirium diagnosis by the primary referring team. Discussion and conclusion. Prevalence of delirium in this population is similar to that observed in other palliative care populations. Also, delirium is the principal determinant of short-term mortality, and it is frequently underdiagnosed. Preventive strategies and early identification could help to reduce its burden
\end{abstract}

Keywords: Advanced cancer, palliative care, delirium, missed delirium, survival.

\section{RESUMEN}

Introducción. El delírium es un trastorno neurocognitivo que frecuentemente se presenta en pacientes con cáncer avanzado. Aumenta la morbilidad, mortalidad y costo, y genera malestar en los pacientes, los miembros de la familia y los profesionales de la salud. A pesar de su impacto, el delírium está subdiagnosticado y, en consecuencia, mal manejado. Objetivo. Describir la prevalencia, características clínicas, impacto en la supervivencia y frecuencia del subdiagnóstico de delírium en pacientes hospitalizados referidos al servicio de cuidados paliativos de un centro oncológico de tercer nivel. Método. Se trata de un estudio prospectivo. Se incluyeron todos los pacientes hospitalizados referidos al servicio de cuidados paliativos del Instituto Nacional de Cancerología en México, desde agosto de 2014 a marzo de 2015. Se recolectaron datos clínicos y sociodemográficos, y se determinó la presencia de delírium utilizando el Confusion Assessment Method. Posteriormente se revisó el expediente clínico para determinar si el equipo primario de referencia había establecido el diagnóstico previo de delírium. Finalmente, treinta días posteriores a la evaluación inicial, se contactó a los pacientes para conocer su estado de supervivencia (vivo/muerto). Se realizó un análisis de supervivencia para comparar la mortalidad de los pacientes con y sin delírium, y se reportó el porcentaje de subdiagnóstico. Resultados. Se incluyeron 174 pacientes, de los que $40.2 \%$ se diagnosticaron con delírium. La supervivencia promedio en pacientes con delírium fue de 11 días, mientras que aquellos sin delírium fue de 21 días; Log Rank 23.50, $p<.001$. Se encontró un subdiagnóstico de $73 \%$ por parte del equipo primario de referencia. Discusión y conclusión. La prevalencia del delirium en esta población es similar a la reportada en otras poblaciones de cuidados paliativos. Además, el delirium es el principal determinante de la mortalidad, y el subdiagnóstico es frecuente. Se requieren estrategias de prevención e identificación temprana del delírium para ayudar a reducir el desgaste que genera.

Palabras clave: Cáncer avanzado, cuidados paliativos, delírium, subdiagnóstico, superviviencia. 


\section{INTRODUCTION}

Delirium is a neurocognitive disorder characterized by an acute or subacute onset and a fluctuating course (Meagher, 2001). Clinical features include a mix of cognitive and behavioral symptoms, including an inability to maintain focus and attention, diminished level of consciousness, global cognitive decline, delusional-hallucinatory phenomena, disturbances in the circadian rhythm, mood swings, and gross disturbances of behavior (Bush et al., 2014; Ramirez-Bermudez et al., 2006). According to its psychomotor presentation, delirium can be classified in hypoactive, hyperactive, or mixed (American Psychiatric Association, 2013). The etiologies of delirium are diverse and multifactorial, usually reflecting the combination of predisposing and precipitating (usually modifiable) causes (Fong, Tulebaev, \& Inouye, 2009).

In oncology palliative care services, delirium is frequently present, with a prevalence varying from $13 \%$ to $42 \%$ on admission, $26-62 \%$ during admission, and up to 58 $88 \%$ in the weeks or hours preceding death (Hosie, Davidson, Agar, Sanderson, \& Phillips, 2013). In this population, delirium can be reversible in $30-50 \%$ of cases (Leonard et al., 2008), since its main etiologies include the use of medications (e.g., opiates, benzodiazepines), infections, electrolytic misbalance, and dehydration (de la Cruz, Ransing, et al., 2015). The frequency of each psychomotor subtype in palliative care patients varies among studies, probably due to different populations and classification criteria. In a sample of 556 palliative care patients (de la Cruz, Ransing, et al., 2015), using DSM-IV TR criteria, the mixed subtype was the most frequent $(45 \%)$, followed by hypoactive $(30 \%)$ and hyperactive $(25 \%)$.

Delirium increases morbidity (Gustafson et al., 1988), causes distress to patients, family members, and health care professionals (Breitbart, Gibson, \& Tremblay, 2002; Bruera et al., 2009). It increases also health expenditure (de la Cruz, Ransing, et al., 2015). Moreover, the presence of delirium diminishes survival in palliative care patients, even as early as 21 days after its onset (Caraceni et al., 2000; Lawlor et al., 2000), and next to performance scales (e.g., Karnofsky Performance Status, Eastern Cooperative Oncology Group Scale), it is an important factor in clinical indexes designed to predict mortality among the same population (Baba et al., 2015; Scarpi et al., 2011). Regardless of the high prevalence reported, delirium is still underdiagnosed and/or mistreated in patients suffering from cancer (Wada, Wada, Wada, \& Onishi, 2010), perhaps because of its fluctuating course and the lack of an intentional search for the syndrome by the health care staff (Inouye, 2006). Besides the impact in patients' outcomes (de la Cruz, Fan, et al., 2015), a non-recognized or mistreated delirium leads to unnecessary treatments and delays in end-of-life issues (Reddy, Nguyen, El Osta, \& Bruera, 2008).
In order to improve the quality of care among oncologic palliative care patients, it is necessary to study the presence of delirium and its impact on survival to develop strategies aimed at prevention, opportune diagnosis, and treatment. Our main goal was to describe the frequency and clinical characteristics of delirium, as well as to analyze its impact on short-term survival (30 days), in a sample of palliative care inpatients treated in a tertiary center. As secondary objectives, we searched for the percentage of missed delirium diagnosis by the primary oncologic team; finally, we sought for correlations between performance indexes and survival rates.

\section{METHOD}

\section{Participants}

We performed a prospective study, including all the inpatients referred to the Palliative Care Service of the Instituto Nacional de Cancerología in Mexico City, from August, 2014 to March, 2015, who were not in deep sedation (Ramsay Sedation Scale $\geq 5$ ). Informed consent was obtained from patients who were able to completely understand the purpose of the study; otherwise, informed consent was obtained from a family member. Admission to a Palliative Care Service requires a diagnosis of advanced stage cancer and: a) score $\geq 3$ in the Eastern Cooperative Oncology Group Scale (ECOG) (Oken et al., 1982) or b) at least two of the next conditions: ECOG score of 2; uncontrolled pain or other significant symptom (e.g., dyspnea, seizures, persistent vomiting); family distress, which is based in clinical judgment, and includes any familiar issue that can affect negatively a patient's wellbeing (e.g., family overload, difficulties in organizing to improve the patient's care); frequent admissions as inpatient in the last months ( $\geq 2$ per month); psychosocial distress, also based in clinical judgment, and includes difficulties in economic, logistic, and emotional areas of the patient (e.g., patient living far away from the hospital and needing physical assistance, psychiatric and psychological symptoms); hospitalization longer than a week without significant improvement (Allende-Pérez, Verástegui-Avilés, Chavira-Estefan, Tejeida-Bautista, \& Dominguez-Ocadio, 2013). When patients are referred to the Palliative Care Service by the leader of a primary referring team (medical oncologist, oncologist surgeon, or haemato-oncologist), a medical palliative care specialist determines their acceptance and then the palliative team performs an evaluation to prescribe the initial treatment.

\section{Instruments and procedure}

Once a patient was included in the Palliative Care Service and the initial assessment was performed, we reviewed the 
clinical file and carried out a short interview to collect clinical and socio-demographic data. We also looked through the medical records to determine if the patient was diagnosed with delirium in the previous five days. Subsequently, the palliative care psychiatrist (OR-M), blinded to the information in the medical file, assessed the patient's status (delirium/non-delirium) using the Spanish version of the Confusion Assessment Method (CAM) (Gonzalez et al., 2004). Patients diagnosed with delirium were also evaluated to determine its subtype in an interview based on DSM5 criteria (hypoactive, hyperactive, or mixed). Finally, the ECOG (Oken et al., 1982) and the Karnofsky Performance Status (Yates, Chalmer, \& McKegney, 1980) were applied to stablish performance status. As per protocol in the Palliative Care Service, patients were evaluated by a physician of the team on a daily basis as inpatients, and once or twice per month after discharge until death. If patients missed an appointment, a call center team (conformed by physicians) contacted them or a family member, so we could know their survival status (alive/dead). If the patient was deceased, a note was written on the electronic clinical file. In June, 2015 we reviewed the clinical files of all the patients included, so we could know their survival status. In the event that a patient had died, we investigated the date of decease to establish the survival time since the initial assessment.

\section{Statistical analysis}

We used descriptive statistics to report socio-demographic data (mean and standard deviation for continuous variables, frequencies and percentages for nominal variables). Differences among groups (delirium/non-delirium) in all categorical and numerical variables were analyzed using $\chi^{2}$ and independent sample $t$ tests, respectively. Any statistically significant difference was posteriorly evaluated as a covariate in a Cox-Regression model. We used the Kaplan-Meier estimate to know the survival function of delirium and non-delirium patients at 30 days of inclusion, and performed a Log-Rank test to determine any statistical significant difference between both groups. Missed diagnosis of delirium by the primary referring team was expressed in percentage. Correlations between medical status (delirium/ non-delirium) and ECOG, Karnofsky Performance Status, or site of primary tumor were performed using $\chi^{2}$. A cutoff point for significance was stablished at $p<.05$. All analyses were performed using the Statistical Package for the Social Sciences (SPSS) version 20.

\section{Ethical considerations}

According to the Mexican Law for clinical research, the study is considered a minimum risk study (Secretaría de Salud, 2014), and was approved by the Ethics Committee of the Instituto Nacional de Cancerología in Mexico City.

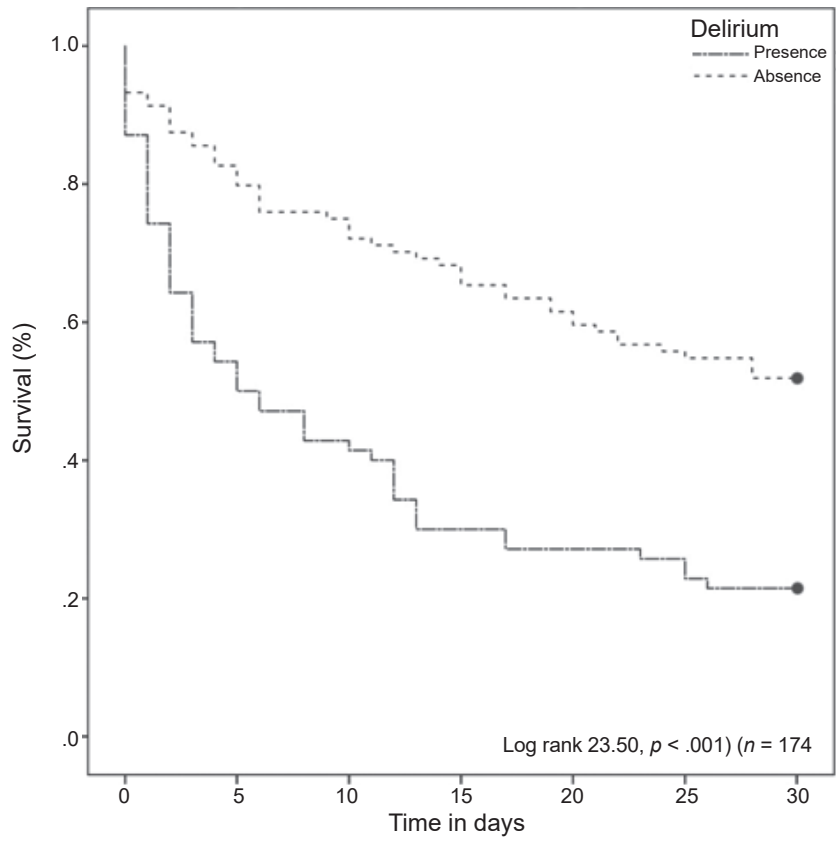

Figure 1. Kaplan-Meier curve of overall survival in patients with delirium versus those who did not had delirium.

\section{RESULTS}

We included 174 patients for initial assessment. Since 22 of them could not be found to determine their survival status, they were included as non-censored cases for the survival analysis. The mean age of the sample was 50.91 years $(S D=16.02)$ and $63.2 \%(n=110)$ were women. Seventy patients $(40.2 \%)$ were diagnosed with delirium, the most frequent subtype corresponded to hypoactive (45.7\%), followed by mixed (42.9\%) and hyperactive (11.4\%).

Mean survival time in patients with delirium was 11 days $[95 \% \mathrm{CI}=8.5,13.9]$ while, in non-delirium patients, it was 21 days, $[95 \% \mathrm{CI}=18.3,22.72]$; Log Rank 23.50, $d f=1, p<.001$. The $t$-test for age showed a significant difference between delirium and non-delirium groups, $M s=55.60,47.75$ respectively, $p<.001$. For the latter, we conducted a Cox-Regression model using age as a covariable. In Cox-Regression, age was not a significant factor $\left(\chi^{2}=.81, d f=1, p=.37\right)$ (Figure 1).

Only $23 \%$ of delirium cases were correctly diagnosed by the primary referring team. The presence of delirium was directly associated with the ECOG score $\left(\chi^{2}=24.28, d f=4\right.$, $p<.001)$ and indirectly associated with the Karnofsky Performance Status $\left(\chi^{2}=43.75, d f=9, p<.001\right)$.

\section{DISCUSSION AND CONCLUSION}

Survival in palliative care population has become an important study topic, as shown by the continuous development of 
indexes to predict survival (Baba et al., 2015). In our study, we found that the presence of delirium at the initial evaluation reduced life expectancy by $50 \%$ at 30 days. These numbers are also in agreement with the findings in other centers of advanced cancer patients (Caraceni et al., 2000; Hui et al., 2012). Age was found as a risk factor for the development of delirium, as previously reported (Elsayem et al., 2010); however, it was not relevant to determine survival. Other studies in advanced cancer patients have also found delirium as the main factor to predict short-term mortality, even when there are not differences between groups' age (de la Cruz, Ransing, et al., 2015; Lawlor et al., 2000).

Our delirium prevalence is similar to those reported in acute palliative care services/units from other countries (de la Cruz, Ransing, et al., 2015; Lawlor et al., 2000). We believe this finding may be due to the fact that these populations share characteristics like advanced cancer stages, age, and low performance status. Although we used a different instrument to diagnose delirium (CAM) than the one used in other studies from acute palliative care services (Memorial Delirium Assessment Scale), previous studies have demonstrated no significant differences among different delirium diagnostic scales (Wong, Holroyd-Leduc, Simel, \& Straus, 2010). The most frequent subtype of delirium was hypoactive, followed closely by the mixed subtype, a similar result to that reported in a larger series (Stagno, Gibson, \& Breitbart, 2004). A possible explanation for this finding is our use of DSM criteria to classify delirium's subtype, and similarities among populations. Other studies have found the mixed subtype as the most frequent (de la Cruz, Ransing, et al., 2015), although they use different methods to establish the delirium subtype. The reason for this discrepancy could be explained by differences in our populations.

Early identification of delirium could reduce mortality (de la Cruz, Ransing, et al., 2015), patient and family distress (Bruera et al., 2009), length and cost of hospitalization (Ely et al., 2001), and caregiver burden (Breitbart et al., 2002). Unfortunately, we found a $73 \%$ of undetected delirium diagnosis in the primary referring team, which is somewhat higher than the $61 \%$ rate found in other centers (de la Cruz, Fan, et al., 2015). This discrepancy could be explained by the sample size, but another possible reason could be that there is a less intentional search for delirium, due to a lack of training or an overload of the health staff. Nevertheless, we believe that continuous education about prevention, early detection, and thorough assessment of delirium will benefit the well-being of palliative care patients (Bush et al., 2014). We could probably benefit from the development and application of clinical guidelines for delirium diagnosis and treatment in this population, similar to those we have in other settings (Secretaría de Salud, 2016).

Finally, we also found that a low performance status (defined by the ECOG and Karnofsky scores) is associated with the presence of delirium. Other studies in palliative care and non-palliative care patients have found this association (de la Cruz, Ransing, et al., 2015), showing that the most frail and sick patients are in greater danger of presenting delirium in palliative care services.

Our study is not without limitations, starting with a relative small sample size compared to other studies (Caraceni et al., 2000; de la Cruz, Fan, et al., 2015). The sample size stopped us from performing more sophisticated analysis, combining several variables (e.g. type of primary tumor, body mass index, etc.) (Agar et al., 2017; Agar et al., 2016; de la Cruz, Ransing, et al., 2015; Maltoni et al., 2005; Perez et al., 2017) to generate a model that predicts mortality. To our knowledge, this is the first description of the prevalence and characteristics of delirium in a Mexican Palliative Care Service. We think that this effort is a step to start in the development of national statistics and new investigations in palliative care patients.

\section{Funding}

No funding was received

\section{Conflict of interests}

Oscar Rodríguez-Mayoral has served as sub-investigator for Ely Lilly and Forum Pharmaceuticals; Francisco Reyes-Madrigal has served as a speaker for Astra Zeneca. The rest of the authors do not report actual or potential conflicts of interest.

\section{Acknowledgments}

The authors would like to thank to Georgina Dominguez, M.D., and Silvia Chavira, M.D. for their valuable collaboration in the development of this paper. Also, we would like to thank all the patients who participated in this study.

\section{REFERENCES}

Agar, M. R., Quinn, S. J., Crawford, G. B., Ritchie, C. S., Phillips, J. L., Collier, A., \& Currow, D. C. (2016). Predictors of Mortality for Delirium in Palliative Care. Journal of Palliative Medicine, 19(11), 1205-1209. doi:10.1089/jpm.2015.0416 Agar, M. R., Lawlor, P. G., Quinn, S., Draper, B., Caplan, G. A., Rowett, D., . . . Currow, D. C. (2017). Efficacy of Oral Risperidone, Haloperidol, or Placebo for Symptoms of Delirium Among Patients in Palliative Care: A Randomized Clinical Trial. JAMA International Medicine, 177(1), 34-42. doi:10.1001/jamainternmed.2016.7491

Allende-Pérez, S., Verástegui-Avilés, E., Chavira-Estefan, S., Tejeida-Bautista, L., \& Dominguez-Ocadio, G. (2013). ¿Cuándo referir a un paciente con cáncer a cuidados paliativos? Gaceta Mexicana de Oncología, 12(4), 280-285.

American Psychiatric Association. (2013). Diagnostic and Statistical Manual of Mental Disorders. Washington, D.C.: American Psychiatric Association.

Baba, M., Maeda, I., Morita, T., Inoue, S., Ikenaga, M., Matsumoto, Y., . . Kinoshita, H. (2015). Survival prediction for advanced cancer patients in the real world: A comparison of the Palliative Prognostic Score, Delirium-Palliative Prognostic Score, Palliative Prognostic Index and modified Prognosis in Palliative Care Study predictor model. European Journal of Cancer, 51(12), 1618-1629. doi:10.1016/j.ejca.2015.04.025

Breitbart, W., Gibson, C., \& Tremblay, A. (2002). The delirium experience: delirium recall and delirium-related distress in hospitalized patients with cancer, their spouses/caregivers, and their nurses. Psychosomatics, 43(3), 183-194. doi:10.1176/appi.psy.43.3.183 
Bruera, E., Bush, S. H., Willey, J., Paraskevopoulos, T., Li, Z., Palmer, J. L., . . . Elsayem, A. (2009). Impact of delirium and recall on the level of distress in patients with advanced cancer and their family caregivers. Cancer, 115(9), 20042012. doi:10.1002/cncr.24215

Bush, S. H., Kanji, S., Pereira, J. L., Davis, D. H., Currow, D. C., Meagher, D. J., . . Lawlor, P. G. (2014). Treating an established episode of delirium in palliative care: expert opinion and review of the current evidence base with recommendations for future development. Journal of pain and symptom management, 48(2), 231-248. doi:10.1016/j.jpainsymman.2013.07.018

Caraceni, A., Nanni, O., Maltoni, M., Piva, L., Indelli, M., Arnoldi, E., . . . De Conno, F. (2000). Impact of delirium on the short term prognosis of advanced cancer patients. Italian Multicenter Study Group on Palliative Care. Cancer, 89(5), 1145-1149.

de la Cruz, M., Fan, J., Yennu, S., Tanco, K., Shin, S., Wu, J., . . Bruera, E. (2015). The frequency of missed delirium in patients referred to palliative care in a comprehensive cancer center. Supportive Care in Cancer, 23(8), 2427-2433. doi:10.1007/s00520-015-2610-3

de la Cruz, M., Ransing, V., Yennu, S., Wu, J., Liu, D., Reddy, A., . . Bruera, E. (2015). The Frequency, Characteristics, and Outcomes Among Cancer Patients With Delirium Admitted to an Acute Palliative Care Unit. The Oncologist, 20(12), 1425-1431. doi:10.1634/theoncologist.2015-0115

Elsayem, A., Mori, M., Parsons, H. A., Munsell, M. F., Hui, D., Delgado-Guay, M. O., ... Bruera, E. (2010). Predictors of inpatient mortality in an acute palliative care unit at a comprehensive cancer center. Supportive Care of Cancer, 18(1), 67-76. doi:10.1007/s00520-009-0631-5

Ely, E. W., Gautam, S., Margolin, R., Francis, J., May, L., Speroff, T., . . Inouye, S. K. (2001). The impact of delirium in the intensive care unit on hospital length of stay. Intensive Care Med, 27(12), 1892-1900. doi:10.1007/s00134-001-1132-2

Fong, T. G., Tulebaev, S. R., \& Inouye, S. K. (2009). Delirium in elderly adults: diagnosis, prevention and treatment. Nature Reviews Neurology, 5(4), 210-220. doi:10.1038/nrneurol.2009.24

Gonzalez, M., de Pablo, J., Fuente, E., Valdes, M., Peri, J. M., Nomdedeu, M., \& Matrai, S. (2004). Instrument for detection of delirium in general hospitals: adaptation of the confusion assessment method. Psychosomatics, 45(5), 426-431. doi:10.1176/appi.psy.45.5.426

Gustafson, Y., Berggren, D., Brannstrom, B., Bucht, G., Norberg, A., Hansson, L. I., \& Winblad, B. (1988). Acute confusional states in elderly patients treated for femoral neck fracture. Journal of the American Geriatrics Society, 36(6), 525-530.

Hosie, A., Davidson, P. M., Agar, M., Sanderson, C. R., \& Phillips, J. (2013). Delirium prevalence, incidence, and implications for screening in specialist palliative care inpatient settings: a systematic review. Palliative Medicine, 27(6), 486498. doi:10.1177/0269216312457214

Hui, D., Kilgore, K., Fellman, B., Urbauer, D., Hall, S., Fajardo, J., . . Bruera, E. (2012). Development and cross-validation of the in-hospital mortality prediction in advanced cancer patients score: a preliminary study. Journal of Palliative Medicine, 15(8), 902-909. doi:10.1089/jpm.2011.0437

Inouye, S. K. (2006). Delirium in older persons. The New England Journal of Medicine, 354(11), 1157-1165. doi:10.1056/NEJMra052321

Lawlor, P. G., Gagnon, B., Mancini, I. L., Pereira, J. L., Hanson, J., Suarez-Almazor, M. E., \& Bruera, E. D. (2000). Occurrence, causes, and outcome of delirium in patients with advanced cancer: a prospective study. Archives of Internal Medicine, 160(6), 786-794.
Leonard, M., Raju, B., Conroy, M., Donnelly, S., Trzepacz, P. T., Saunders, J., \& Meagher, D. (2008). Reversibility of delirium in terminally ill patients and predictors of mortality. Palliative Medicine, 22(7), 848-854. doi: $10.1177 / 0269216308094520$

Maltoni, M., Caraceni, A., Brunelli, C., Broeckaert, B., Christakis, N., Eychmueller, S., . . Kaasa, S. (2005). Prognostic factors in advanced cancer patients: evidence-based clinical recommendations--a study by the Steering Committee of the European Association for Palliative Care. Journal of Clinical Oncology, 23(25), 6240-6248. doi:10.1200/JCO.2005.06.866

Meagher, D. J. (2001). Delirium: optimising management. British Medical Journal, 322(7279), 144-149.

Oken, M. M., Creech, R. H., Tormey, D. C., Horton, J., Davis, T. E., McFadden, E. T., \& Carbone, P. P. (1982). Toxicity and response criteria of the Eastern Cooperative Oncology Group. American Journal of Clinical Oncology, 5(6), 649-655.

Perez, D. A., Allende, S. R., Rivera, M. M., Alvarez, N. E., Urbalejo, V. I., \& Figueroa Baldenegro, L. E. (2017). Phase Angle of Bioelectrical Impedance Analysis as Prognostic Factor in Palliative Care Patients at the National Cancer Institute in Mexico. Nutrition and Cancer, 69(4), 601-606. doi:10.1080/01635581.201 7.1299880

Ramirez-Bermudez, J., Lopez-Gomez, M., Sosa Ana, L., Aceves, S., Nader-Kawachi, J., \& Nicolini, H. (2006). Frequency of delirium in a neurological emergency room. The Journal of Neuropsychiatry and Clinical Neurosciences, 18(1), 108112. doi:10.1176/jnp.18.1.108

Reddy, S. K., Nguyen, N., El Osta, B., \& Bruera, E. (2008). Opioids masquerading as delirium in a patient with cancer pain and obstructive sleep apnea. Journal of Palliative Medicine, 11(7), 1043-1045. doi:10.1089/jpm.2008.9864

Scarpi, E., Maltoni, M., Miceli, R., Mariani, L., Caraceni, A., Amadori, D., \& Nanni, O. (2011). Survival prediction for terminally ill cancer patients: revision of the palliative prognostic score with incorporation of delirium. Oncologist, 16(12), 1793-1799. doi:10.1634/theoncologist.2011-0130

Secretaría de Salud. (2014). Reglamento de la Ley General de Salud en Materia de Investigación para la Salud. Retrieved from: http://www.salud.gob.mx/unidades/cdi/nom/compi/rlgsmis.html

Secretaría de Salud. (2016). Prevención, diagnóstico y tratamiento del delirium en el adulto mayor hospitalizado. Retrieved from: http://www.cenetec.salud.gob.mx/ descargas/gpc/CatalogoMaestro/465-11_Delirium_en_al_anciano/IMSSx5S3. PDF

Stagno, D., Gibson, C., \& Breitbart, W. (2004). The delirium subtypes: a review of prevalence, phenomenology, pathophysiology, and treatment response. Palliative \& Supportive Care, 2(2), 171-179.

Wada, T., Wada, M., Wada, M., \& Onishi, H. (2010). Characteristics, interventions, and outcomes of misdiagnosed delirium in cancer patients. Palliative \& Supportive Care, 8(2), 125-131. doi:10.1017/S1478951509990861

Wong, C. L., Holroyd-Leduc, J., Simel, D. L., \& Straus, S. E. (2010). Does this patient have delirium?: value of bedside instruments. JAMA, 304(7), 779-786. doi:10.1001/jama.2010.1182

Yates, J. W., Chalmer, B., \& McKegney, F. P. (1980). Evaluation of patients with advanced cancer using the Karnofsky performance status. Cancer, 45(8), 22202224. 